\title{
Tratamento Biológico de Efluentes de Indústrias de Papel Após Floculação e Coagulação com Sais de Alumínio e Polieletrólitos Naturais
}

\author{
Edson M. dos Reis e Jorge Nozaki* \\ (*) Departamento de Química-Universidade Estadual de Maringá.Av. Colombo, 5790. CEP:87020-900 Maringá- \\ PR - Brasil
}

\begin{abstract}
The flocculation and sedimentation of recalcitrant organic compounds of high molecular weight using natural polyelectrolytes, extracted from the cactus Cereus peruvianus and Opuntia ficus indica, have been studied. Organic compounds of high molecular weight from effluents of paper and pulp industries are difficult for biological degradation. However, using a mixture of aluminum salts and natural polyelectrolytes, the aggregation and settling properties of recalcitrant organics were increased if compared with conventional methods of wastewater treatment using only aluminum or iron sulfate. After flocculation, sedimentation, and filtration, the effluent was submitted to biological degradation by activated sludge process. The main advantages of using a mixture of aluminum salts and natural polyelectrolytes were shorter time of flocculation, floccus of larger size and easier for filtration.The removal efficiency observed were:85-90\% of aromatic compounds, 70-85\% of chemical oxygen demand,and 91$97 \%$ of colour.
\end{abstract}

Key words: flocculation; natural polyelectrolytes; biological degradation; activated sludge process, paper and pulp effluents

\section{INTRODUÇÃO}

Compostos organicos de altos pesos moleculares, tais como as ligninas provenientes dos efluentes das indústrias de papel e celulose são difíceis de serem biodegradados por processos aeróbicos ou anaeróbicos (MITTAR et $a l$, 1992). A composição destes efluentes, principalmente os oriundos do processo Kraft, é complexa e de elevada toxicidade para a biota aquática pela presença das ligninas, polifenóis, sulfetos, compostos organoclorados, cloro residual, etc., (STEPHENSON and DUFF, 1996). A presença de organoclorados e outras substâncias tóxicas dificultam o tratamento biológico, pois atuam como bactericidas e fungicidas. Por estas razões, o método biológico para o tratamento destes efluentes tem baixa eficiência, necessitando normalmente longos tempos de retenção com eficiência máxima da ordem de 40-50\% da remoção de DQO (NORTON, 1992).
Os polieletrólitos naturais foram utilizados desde 2000 A.C., onde Strychno potatorium Linn extraído de sementes era usado como clarificador de água (RODRIGUES, 1984). Após a crise do petróleo em 1970-1980, a substituição dos polieletrólitos sintéticos pelos produtos naturais tem recebido considerável atenção. Várias fontes de polieletrólitos naturais foram pesquisadas tais como o Floccotan, extraído do quebracho Schinopsis lorentziu e quimicamente modificado, sendo bastante utilizado como clarificador de águas na América do Sul. O cactus Cereus peruvianus natural da Argentina e Brasil fornece um polieletrólito bastante viscoso que é utilizado em tratamento de águas como auxiliares de floculação e coagulação (NOZAKI et al, 1993).

Os sais de alumínio utilizados em tratamento de água são tóxicos para a biota aquática e, várias tentativas foram desenvolvidas para suprimir ou reduzir o seu consumo em estações de tratamento, por exemplo, a utilização de

\footnotetext{
* Author for correspondence
} 
biopolímeros como a Chitosan (HUANG \& CHEN, 1996), e a substituição dos sais de alumínio pelo sulfato ou cloreto férrico (STEPHENSON and DUFF, 1996).

Neste trabalho, procurou-se desenvolver uma metodologia para a redução do consumo dos sais de alumínio, utilizando-se como auxiliares de floculação e coagulação os polieletrólitos naturais extraídos dos cactus Cereus peruvianus e Ficus opúntia Indica. Em função do baixo custo, estes polieletrólitos substituem com vantagens a utilização da Chitosan em tratamento de águas.

\section{MATERIAIS E MÉTODOS}

\section{Estudos de floculação com polieletrólitos naturais}

Em béqueres de $2000 \mathrm{ml}$ contendo água foram colocados cerca de $430 \mathrm{~g}$ da polpa interna do cactus, cortados em pequenos pedaços, e mantidos durante 24 horas. Filtrou-se, e o líquido viscoso foi homogeneizado no aparelho para o teste de jarras Milan JT 101. Estas soluções foram mantidas em refrigerador sendo então feitas diluições adequadas, momentos antes de iniciar cada experimento.

Experimento A). No aparelho para o teste de jarras, adaptados com 6 béqueres de $1000 \mathrm{ml}$, foram colocados $600 \mathrm{ml}$ da amostra do efluente (canal central) em cada béquer, sendo então agitados por 1 minuto para homogeneização. Em cada frasco foram adicionados respectivamente: $250 \mathrm{mg} / \mathrm{l}$ de cloreto de alumínio e concentrações variadas do polieletrólito natural extraído do cactus Cereus peruvianus. Os frascos foram agitados vigorosamente por 15 minutos, desligando-se então o aparelho de Jar test. Após 60 minutos de decantação, foram observadas as alturas e os aspectos dos sólidos decantados com auxílio de uma régua e leituras de absorvâncias do líquido sobrenadante em $270 \mathrm{~nm}$ no espectrofotômetro Beckman-DU-70, com cubetas de quartzo de $1 \mathrm{~cm}$.

Experimento B). O mesmo experimento foi conduzido com as mesmas soluções, porém, utilizando-se o polieletrólito natural obtido do Ficus opuntia Indica.
Experimento C). Nos 6 béqueres de $1000 \mathrm{ml}$, foram colocados $600 \mathrm{ml}$ da amostra do efluente (canal central) em cada frasco,sendo agitados por 1 minuto em velocidade máxima de agitação segundo o modelo JT 101. Nos três primeiros béqueres foram adicionados respectivamente: $250 \mathrm{mg} / \mathrm{l}$ de sulfato de alumínio; $250 \mathrm{mg} / \mathrm{l} \mathrm{de}$ cloreto de alumínio e $250 \mathrm{mg} / \mathrm{l}$ de sulfato férrico. Nos restantes foram adicionados respectivamente: $250 \mathrm{mg} / \mathrm{l}$ de cada sal e $2,5 \mathrm{mg} / \mathrm{l}$ do polieletrólito natural extraído do cactus Cereus peruvianus. Os frascos foram agitados por 15 minutos, desligando-se o Jar test e considerando-se este tempo como $(\mathrm{t})=0$. Foram medidas as alturas dos flocos formados e os tempos gastos em cada béquer para o processo de floculação, coagulação e decantação total. A seguir, foram feitas leituras de absorvâncias do sobrenadante em $270 \mathrm{~nm}$.

Experimento D). Nos frascos contendo $600 \mathrm{ml}$ do efluente (canal central), foram utilizadas soluções de ácido clorídrico e hidróxido de sódio para o ajuste do $\mathrm{pH}$ em 6, 7, 8, 9, 10 e 11 respectivamente. Adicionaram-se $250 \mathrm{mg} / \mathrm{l}$ do cloreto de alumínio e $2,5 \mathrm{mg} / \mathrm{l}$ do polieletrólito agitando-se por 15 minutos. Após 60 minutos de decantação, foram observados em cada frasco: a altura e o aspecto do sólido, tipo dos flocos formados e leitura da absorvância do sobrenadante em $270 \mathrm{~nm}$.

Experimento E). Nos 6 béqueres do Jar test, após o ajuste do $\mathrm{pH}$ no intervalo de 7,2-7,8 foram adicionados $2,5 \mathrm{mg} / \mathrm{l}$ do polieletrólito e concentrações de cloreto de alumínio de: 0,175 , $200,225,250$ e $275 \mathrm{mg} / \mathrm{l}$ respectivamente. Após 15 minutos de agitação e 60 minutos de decantação, as soluções foram filtradas, isolando-se o lodo. No sobrenadante foram feitas leituras de absorvâncias em $270 \mathrm{~nm}$ e determinações da demanda química do oxigênio (DQO) (APHA-AWWA, 1989). A seguir, outros experimentos foram desenvolvidos com a mesmas metodologias para a determinação das concentrações ótimas em mg/l para os sulfatos de alumínio e ferro(III).

Tratamento biológico do efluente final por lodos ativados

Após a separação do lodo decantado, os filtrados foram submetidos ao tratamento por lodos ativados. Os inóculos foram coletados na lagoa 
de lodos ativados da Indústria de papel Klabin em Telêmaco Borba-PR. Para o tratamento do efluente, utilizou-se um reator de bancada construído em vidro comum e volume útil de 3 litros, um decantador com volume de 0,8 litros, uma bomba peristáltica Milan-BP-204 para a alimentação do sistema e uma bomba de aquário como aerador, conforme se observa na figura 1 . O filtrado foi inicialmente diluído com água na proporção de 1:2, adicionando-se $140 \mathrm{mg} / \mathrm{l}$ de açúcar comercial, $12 \mathrm{mg} / \mathrm{l}$ de nitrogênio na forma de uréia e $2,5 \mathrm{mg} / \mathrm{l}$ de fósforo na forma de fosfato de potássio, seguindo a relação de DQO:N:P em 100:5:1 respectivamente. Após a adição dos alimentos, o pH foi ajustado na faixa de 7,2-7,8. Após 20 dias de alimentação, diminuiu-se gradativamente a concentração do açúcar comercial.

\section{Recuperação do alumínio no lodo formado pela decantação}

Para a recuperação do alumínio no lodo isolado anteriormente, tratou-se o lodo com solução de ácido clorídrico até a dissolução total. Com a adição gradual do $\mathrm{NaOH}$ e agitação branda, ocorreu a precipitação do $\mathrm{Al}(\mathrm{OH})_{3}$ que após a decantação foi separado do sobrenadante. $\mathrm{O}$ hidróxido gelatinoso foi secado a $110^{\circ} \mathrm{C}$ para o seu reaproveitamento no processo.

\section{RESULTADOS E DISCUSSÃO}

Os efluentes coletados em diferentes pontos da fábrica de papel da Klabin S.A. tem características diferenciadas de $\mathrm{pH}$ e DQO conforme se observa pela tabela 1. Para a floculação e coagulação o pH ótimo observado foi no intervalo de 9-10, ocorrendo também boa eficiência em outros valores de $\mathrm{pH}$. A adição de sais de alumínio sobre o efluente tende a reduzir o pH da solução (tabela 2). Os dados de remoção da DQO e compostos aromáticos foram obtidos sem o ajuste do $\mathrm{pH}$ durante a floculação, conforme se observa nas figuras 3 e 4. Ajustando-se o pH para 9-10 durante a floculação e decantação, a eficiência de remoção seria maior, porém, o custo do tratamento seria proporcionalmente maior.

A concentração mínima e necessária para o polieletrólito natural foi de $2,5 \mathrm{mg} / \mathrm{l}$. Concentrações mais elevadas não aumentaram significativamente o processo de floculação e decantação, embora esta seja importante na etapa do tratamento biológico, pois trata-se de um material facilmente biodegradável. Observou-se também que 15 minutos foi o tempo mínimo para uma boa floculação e decantação na presença do polieletrólito, e 60 minutos na ausência do mesmo (figura 2), não se observando diferenças significativas entre os polieletrólitos extraídos dos cactus Cereus peruvianus ou Ficus opuntia Indica. Observou-se também que o polieletrólito não atua com eficiência isoladamente sendo necessária a presença do sal de alumínio.

O tratamento biológico por lodos ativados do líquido sobrenadante após a floculação, decantação e separação dos compostos de alto peso molecular, tem a vantagem de evitar a presença dos compostos refratários junto aos microorganismos no reator biológico (figura 6). Entretanto, com a remoção gradual do alimento artificial (açúcar comercial), observou-se uma diminuição acentuada da massa dos microorganismos no reator (SSV). A redução dos sólidos suspensos voláteis (SSV) no reator indicou que mesmo os compostos de baixo peso molecular, como as ligninas do líquido sobrenadante, não são facilmente digeridas pelas bactérias aeróbicas. Para a solução do problema, separou-se o efluente oriundo da fábrica de papel, com pH 7,5 e DQO de $400 \mathrm{mg} / \mathrm{l}$ e baixos teores de ligninas (tabela 1). Este efluente, composto basicamente basicamente de celulose e hemicelulose é de fácil biodegradação, constituindo-se em excelente substituto para o açúcar comercial.

\section{CONCLUSÕES}

$\mathrm{Na}$ figura 5 não são observadas diferenças acentuadas nas remoções de DQO e compostos aromáticos com sais de alumínio em presença ou ausência de polieletrólitos. Entretanto, as seguintes vantagens na utilização dos polieletrólitos poderiam ser destacadas: formação de flocos maiores e mais densos, rapidez na floculação, decantação e, maior facilidade em filtrações. Considerando-se o caráter não tóxico dos polieletrólitos naturais e a sua facilidade em biodegradação, sua presença é também importante no tratamento biológico por lodos ativados. 
Tabela 1. Características dos efluentes da Indústria de papel Klabin

\begin{tabular}{lccc}
\hline Ponto da amostragem & vazão $\left(\mathbf{m}^{\mathbf{3}} \mathbf{/ h}\right)$ & pH & DQO $(\mathbf{m g} / \mathbf{l})(*)$ \\
\hline Canal da celulose & 200 & 7,60 & 1.440 \\
Canal central & 500 & 9,00 & 1.477 \\
Canal do branqueamento & 270 & 11,00 & 1.354 \\
Máquina de papel & 300 & 7,50 & 400 \\
Efluente final (**) & 2.530 & 7,30 & 904 \\
\hline
\end{tabular}

(*) Média de 5 determinações. (**) O efluente final era constituído pelos efluentes anteriores.

Tabela 2. Testes de floculação e decantação para o efluente do canal de branqueamento da indústria Klabin (*)

\begin{tabular}{cccccc}
$\begin{array}{c}{\left[\mathrm{AlCl}_{3}\right]} \\
\mathrm{mg} / \mathrm{l}\end{array}$ & $\begin{array}{c}\text { Absorvância } \\
\text { em 270 nm }\end{array}$ & $\begin{array}{c}\text { \% de aromáticos } \\
\text { removidos }\end{array}$ & $\begin{array}{c}\text { DQO residual } \\
\mathrm{mg} / 1(* *)\end{array}$ & $\begin{array}{c}\text { \% de DQO } \\
\text { removidos }\end{array}$ & $\mathrm{pH}$ \\
\hline$(* * *)$ & 2,91 & $\ldots \ldots \ldots \ldots \ldots$ & 1.354 & $\ldots \ldots$ & 11,0 \\
1450 & 0,452 & 84,5 & 380 & 71,8 & 5,9 \\
1500 & 0,365 & 87,4 & 361 & 73,3 & 5,1 \\
1550 & 0,331 & 88,6 & 322 & 76,2 & 4,7 \\
1650 & 0,313 & 89,2 & 328 & 76,8 & 4,3 \\
1750 & 0,314 & 89,2 & 360 & 73,3 & 4,2 \\
\hline
\end{tabular}

(*) Foram variadas as concentrações do $\mathrm{AlCl}_{3}$, mantendo-se constante a concentração do polieletrólito natural em 2,5 mg/l em todos os frascos. (**) Média de 5 determinações. (***) Amostra original sem adição do sal ou polieletrólito.

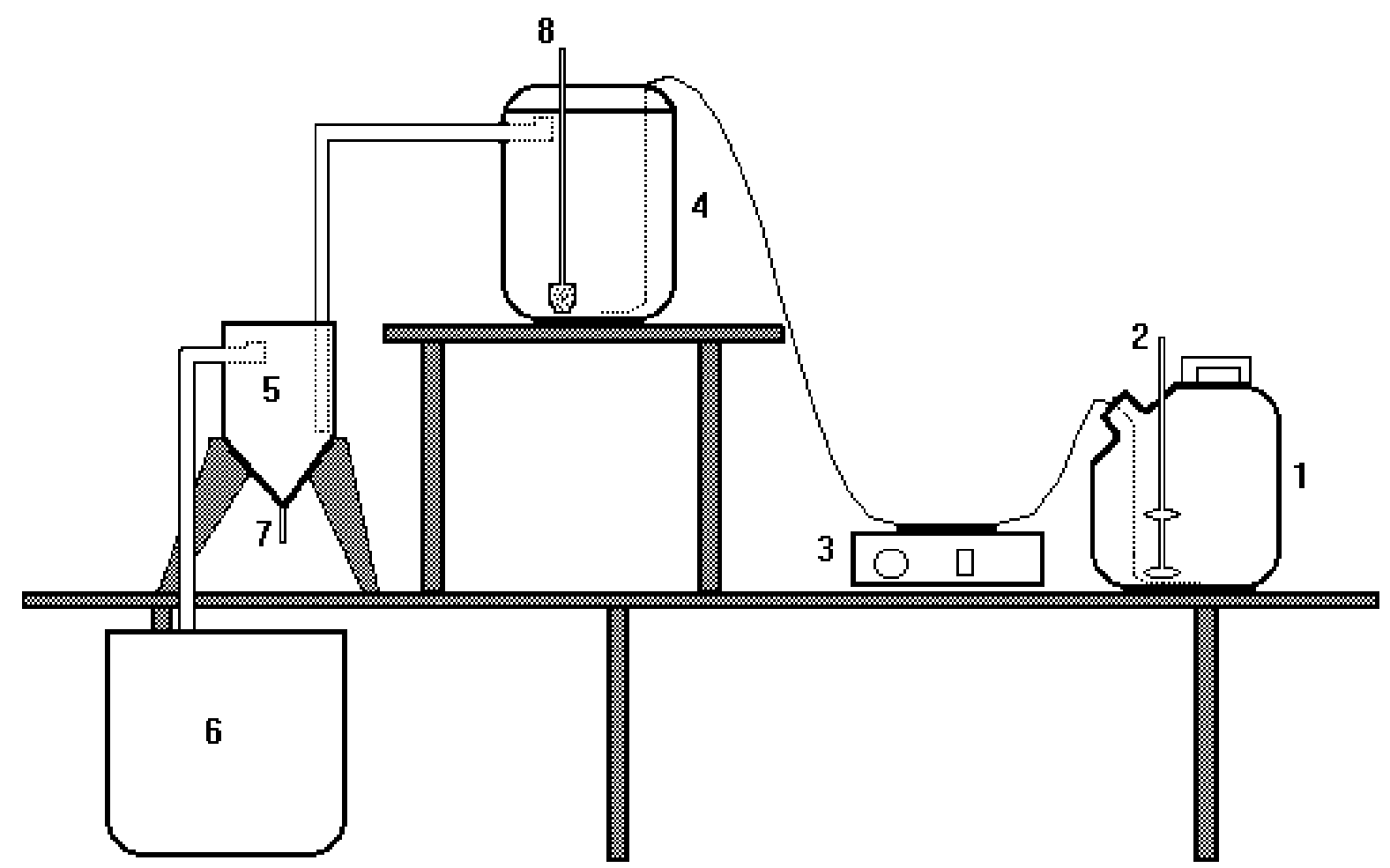

Figura 1. Reator de bancada para o tratamento biológico de efluentes por lodos ativados.(1) frasco de alimentos, (2) agitador, (3) bomba peristáltica, (4) reator, (5)decantador, (6) efluente final, (7) reciclo do lodo e (8)aerador. 


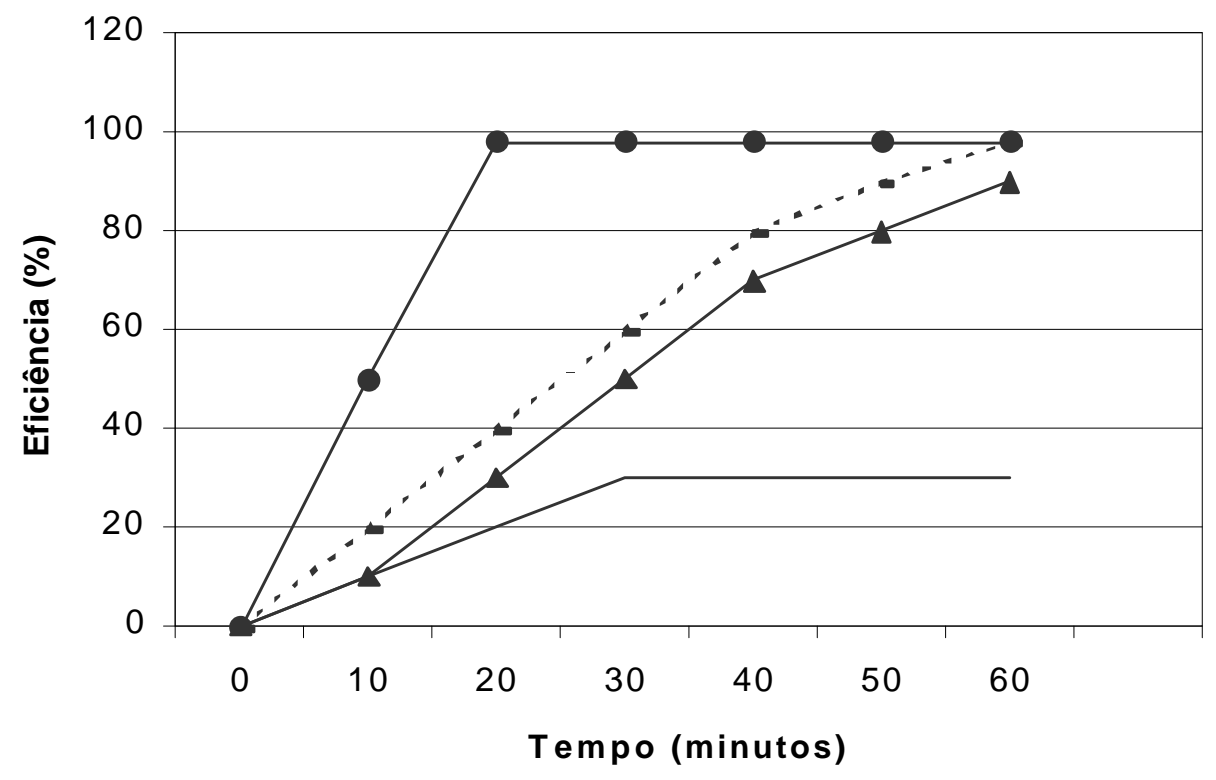

- = Efluente + cloreto de alumínio + polieletrólito natural. $\ldots$ = Efluente + cloreto de alumínio, $\bullet=$ Efluente + sulfato férrico. $-=$ Efluente + polieletrólito natural.

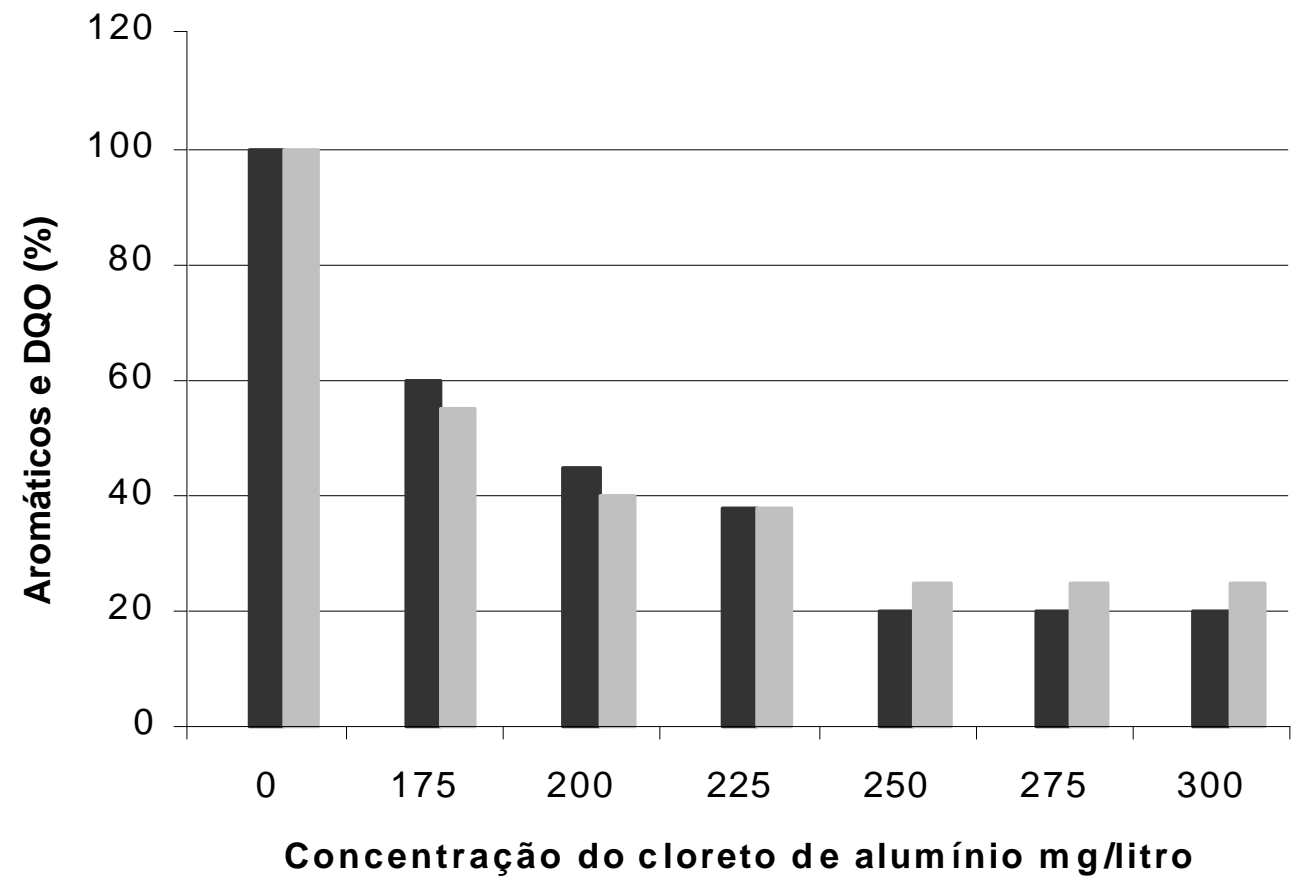

Figura 3.Floculação e decantação do efluente final com $\mathrm{AlCl}_{3}$ e polieletrólitos. As duas primeiras colunas $(0$ p.p.m. de $\mathrm{AlCl}_{3}$ ) referem-se à amostra original. Para as demais, as colunas escuras referem-se aos compostos aromáticos remanescentes em (\%) e as cinzas aos valores de DQO remanescentes após os tratamentos. 


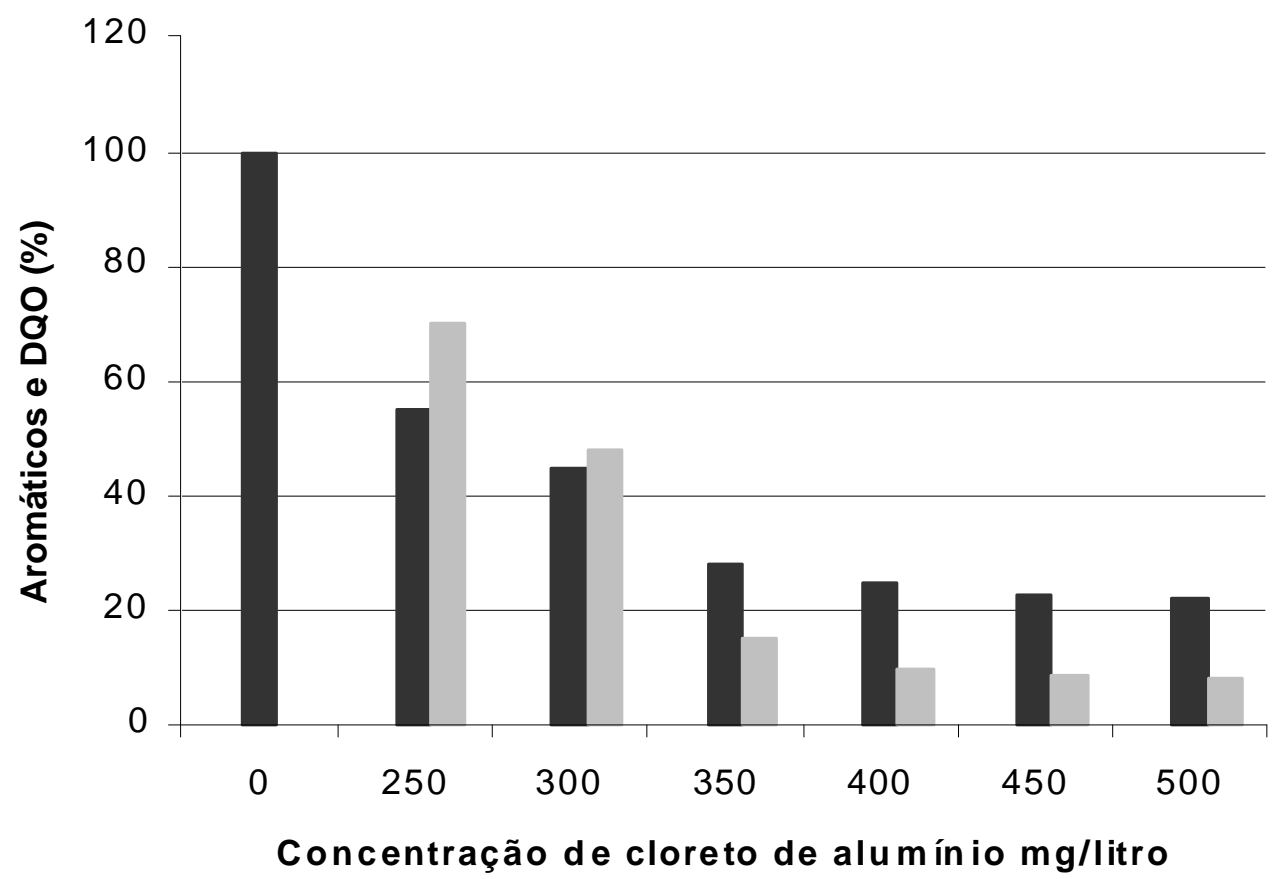

Figura 4. Floculação e decantação do efluente do canal da celulose com $\mathrm{AlCl}_{3}$ e polieletrólitos. A primeira coluna corresponde à amostra original. Para as demais, as colunas escuras correspondem aos aromáticos e as cinzas aos valores de DQO remanescentes em (\%).

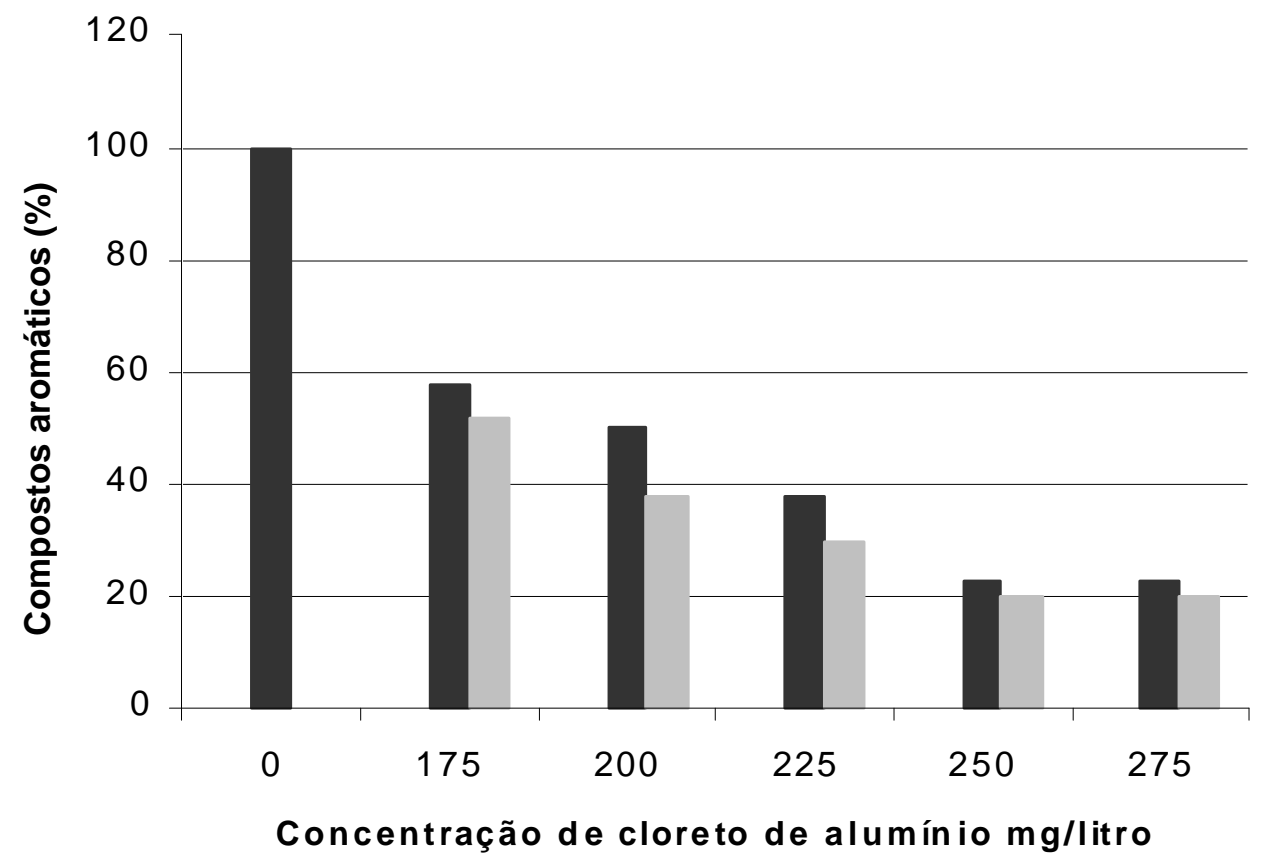

Figura 5. Remoção dos compostos aromáticos pela floculação e decantação com cloreto de alumínio e polieletrólitos naturais. A primeira coluna refere-se à amostra original. As colunas escuras referem-se ao percentual de aromáticos remanescentes após o tratamento com $\mathrm{AlCl}_{3}$ e $2,5 \mathrm{mg} / \mathrm{l}$ de polieletrólitos naturais. 


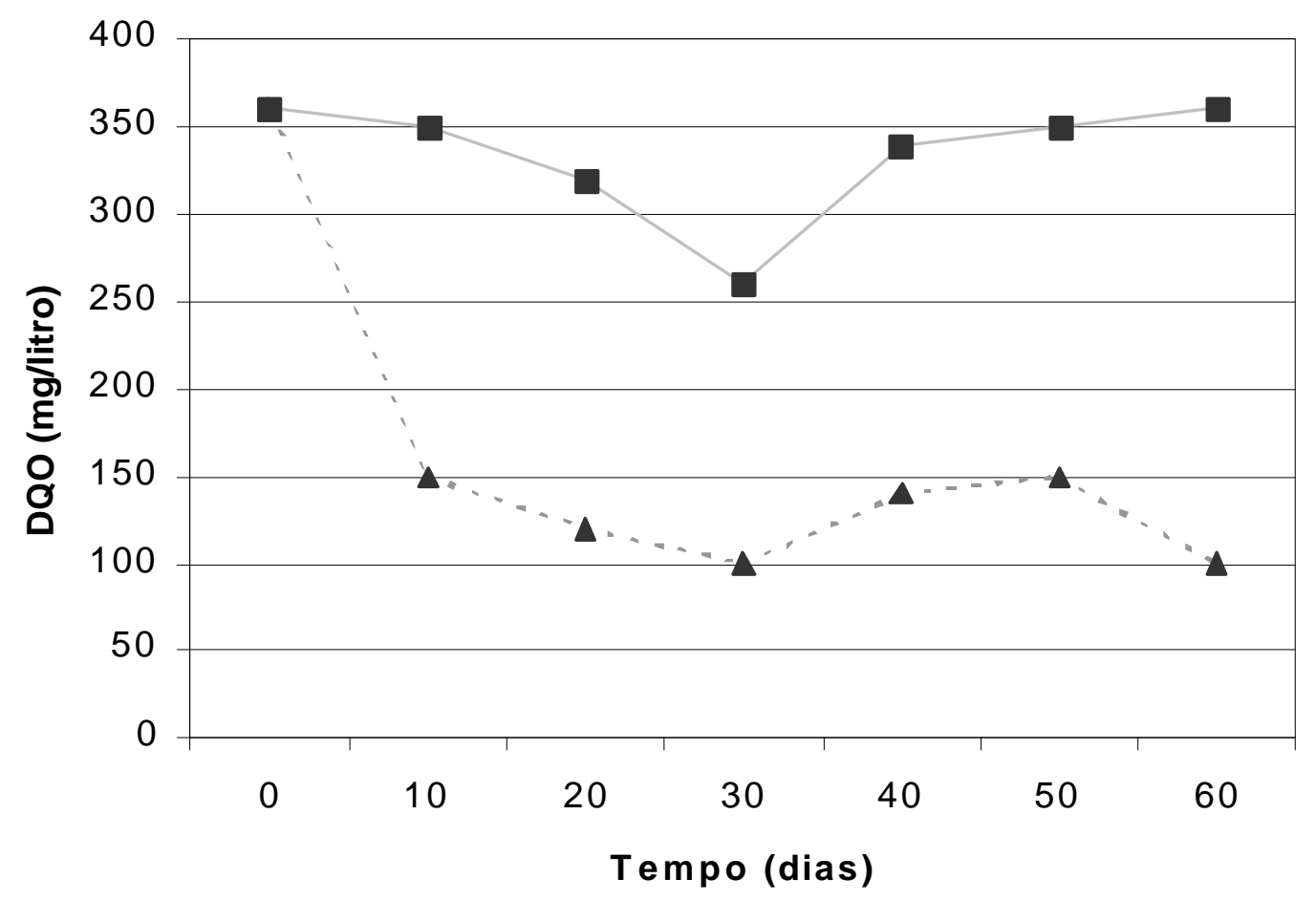

Figura 6. Tratamento biológico do líquido sobrenadante do canal de branqueamento após a floculação e decantação com $\mathrm{AlCl}_{3}$ e polieletrólitos naturais. ..... = DQO $(\mathrm{mg} / \mathrm{l})$ final. = DQO de entrada no reator.

\section{AGRADECIMENTOS}

Os autores agradecem ao CNPq e MMA pelo apoio financeiro, e a Indústria Klabin S.A. pelo fornecimento das amostras de efluentes

\section{REFERÊNCIAS BIBLIOGRÁFICAS}

APHA-AWWA (1989), Standard Methods for the Examination of Water and Wastewater, Boston: APHA-AWWA, 1193pp.

Huang, C. \& Chen, Y.(1996), Coagulation of colloidal particles in water by chitosan. J.Chem.Tech. Biotechnol.,66, 227-232.

Mittar,D.; Khanna,P.K.; Marwaha,S.S. \& Kennedy, J.F. (1992), Biobleaching of pulp and paper mill effluents by Phanerochaete chrysosporium. J.Chem. Tech. Biotechnol., 53, 81-92.

Norton, S.C. (1992), Pulp and paper effluent management. Water Environment Research, 64, (4), 429-439.
Nozaki, J., Messerschmidt, I. e Rodrigues, D.G. (1993) , Remoção de poluentes em efluentes de curtumes com polieletrólitos naturais. Estudos de especiação química do cromo. Arquivos de Biologia e Tecnologia, 36, (4), 761-770.

Rodrigues, D.G.(1984), Polieletrólitos naturais. Dissertação de Mestrado, Departamento de Engenharia Sanitária-UFMG.

Stephenson, R. J. and Duff, S. J. B. (1996), Coagulation and precipitation of a mechanical pulping effluent-I. Removal of carbon, colour and turbidity. Wat. Res.,30, (4), 781792.

Stephenson, R. J. and Duff, S. J. B. (1996), Coagulation and precipitation of a mechanical pulping effluent-II. Toxicity removal and metal salt recovery. Wat. Res.,30, (4), 793798. 